\title{
Autofagia celular em processos patológicos
}

\section{Cellular autophagy in pathological processes}

\author{
Selma Giorgio ${ }^{1}$
}

\begin{abstract}
Resumo
As pesquisas atuais sobre autofagia, um processo catabólico complexo, indicam que é um fenômeno vital para todos os organismos. Sabe-se que a célula se "auto-canabaliza", englobando porções de seu citoplasma ou até de organelas inteiras, em estruturas denominadas autofagolisossomos, e as macromoléculas, resultantes da degradação por hidrolases lisossomais, são fonte de energia celular em distintas situações. A autofagia é responsável também pela auto-limpeza celular, removendo agregados macromoleculares mal formados. Estudos recentes demonstraram que em situações de estresse como a desnutrição ou a falta de oxigênio, nas doenças neurodegenerativas e no câncer, a autofagia desempenha papel importante. Nesta revisão são abordados aspectos estruturais e moleculares da autofagia, as técnicas atuais de detecção e o envolvimento em processos patológicos, principalmente infecciosos. Bactérias tais como Streptococcus pyogenes, Salmonella entérica, Listeria monocytogenes e os vírus da hepatite $\mathrm{C}$ e herpes simplex induzem autofagia nas células infectadas. O parasita Leishmania amazonensis que infecta macrófagos e causa a leishmaniose cutânea em humanos, também induz autofagia nas células infectadas e em tecido cutâneo de modelo experimental, sendo que o tratamento das células com inibidor da autofagia diminui a carga parasitária. Conclui-se, a partir dos resultados aqui revisados e discutidos, que a modulação da autofagia é importante na evolução de várias doenças infecciosas. O caminho está aberto para o desenvolvimento de compostos que modulem o processo autofágico em humanos, e que possam intervir no desenvolvimento de varias doenças.
\end{abstract}

Palavras-Chaves: Autofagia. Doenças Infecciosas. Doenças Neurodegenerativas. Câncer.

\begin{abstract}
Current research investigating autophagy, a complex catabolic process, indicates a vital role for this phenomenon. It is known that during the "self-eating" process, cell isolates portions of the cytoplasm or whole organelles in structures called autophagolisosomes, which are degraded by lysosomal hydrolases into macromolecules as an energy source during different situations. Autophagy is also responsible for cellular "self-cleaning" by removal of malformed macromolecular aggregates. Several recent studies have shown that during stress such as malnutrition or lack of oxygen and neurodegenerative diseases and cancer, autophagy plays an important role. In this review, structural and molecular aspects of autophagy, current detection techniques and their involvement in pathological processes, with emphasis in infectious diseases, are discussed. Bacteria such as Streptococcus pyogenes, Salmonella enterica, Listeria monocytogenes and hepatitis $\mathrm{C}$ virus and herpes simplex virus induce autophagy in infected cells. Leishmania amazonensis a parasite of macrophages causes cutaneous leishmaniasis in humans, induce autophagy in infected cells and skin tissue of experimental model; autophagy inhibitor treatment reduces the macrophage parasite load. These results provide evidences that autophagy modulation is important in the course of various infectious diseases, and perspectives of autophagy modulators treatments against various diseases in humans.
\end{abstract}

Key-words: Autophagy. Infectious diseases. Neurodegenerative diseases. Cancer

${ }^{1}$ Doutora em Ciências Biológicas (Imunologia e Biologia Molecular). Professora Associada no Instituto de Biologia da Universidade Estadual de Campinas. Email: sgiorgio@unicamp.br 


\section{Introdução}

Autofagia é uma palavra de origem grega que significa comer a si mesmo (auto $=\mathrm{eu}$, próprio, e fagia $=$ comer $)$ isto é, auto-canabalização (LEVINE; YUAN, 2005). As células para sobreviverem adequadamente, precisam manter a homeostase (equilíbrio e organização funcionais), e um dos recursos usados é fazer autofagia (MIZUSHIMA, 2007). As células de todos os seres vivos fazem autofagia em diversas circunstancias, como quando há um acumulo de grandes agregados protéicos e de organelas defeituosas ou em situações de estresse, como escassez de alimento, pouco oxigênio, temperaturas muito elevadas ou infecções (LEVINE, 2007; LEVINE; MIZUSHIMA, 2007). Pesquisadores iniciaram os estudos sobre autofagia nos anos de 1950 e 1960, quando observaram aspectos morfológicos desse fenômeno biológico em fígado de ratos normais e, com maior freqüência, em fígado de ratos desnutridos, presença de hepatócitos com vesículas circundando mitocôndrias e reticulo endoplasmático semi- desintegrados. De Duve cunhou o termo autofagia em 1963 em Londres durante um simpósio sobre lisossomos, para descrever a ocorrência dessas estruturas que estavam associadas aos lisossomos (NOVIKOFF, 1959; De DUVE; WATTIAUX, 1966; ASHFORD; PORTER, 1962; KLIONSKY， 2008; YANG; KLIONSKY, 2010). Nos últimos 15 anos as pesquisas sobre autofagia se intensificaram devido, principalmente, aos métodos moleculares e genéticos que permitem a detecção e manipulação de fases do processo autofágico (YANG; KLIONSKY, 2010). O numero de artigos sobre o tema aumentou significativamente e em 2005 foi lançada uma revista cientifica com o titulo "Autophagy". Desta forma, a presente revisão tem como objetivo abordar aspectos estruturais e moleculares da autofagia, as técnicas atuais de detecção e o seu envolvimento em processos patológicos, principalmente infecciosos.

\section{Materiais e Métodos}

A pesquisa bibliográfica foi realizada utilizando a base de dados PubMed, usando-se as seguintes palavras-chave: "autophagy", combinada com "review", "pathogen", "parasite" e "Leishmania" e selecionado-se o período de 1959 a agosto de 2013.

\section{Desenvolvimento}

\section{Aspectos estruturais da autofagia}

Células em tecidos ou meios de cultivo pobres em nutrientes, para sobreviver, realizam autofagia e durante o processo englobam e degradam porções de seu próprio citoplasma. Essas porções citoplasmáticas, que podem até incluir organelas inteiras, são englobadas por uma membrana com dupla bicamada lipídica que se alonga e expande circundando a área, ocorrendo o fechamento, que resulta em um compartimento delimitado, denominado vacúolo autofágico ou autofagossomo (LEVINE; KLIONSKY, 2004; LEVINE; YUAN, 2005) (Figura 1). A origem da membrana ainda é controversa, alguns pesquisadores sugerem que a fonte seja a membrana do reticulo endoplasmático ou do complexo de Golgi, enquanto outros sugerem que seja a membrana das mitocôndrias e de pequenas vesículas que circulam livres pelo citoplasma (LEVINE \& YUAN, 2005; RUBINSZTEIN et al., 2007). A porção externa do autofagossomo vai se fundir com endossomos e lisossomos originando o autolisossomo ou autofagolisossomo (LEVINE; MIZUSHIMA; VIRGIN, 2011) onde o material interno e a membrana serão completamente degradados pelas enzimas hidrolases lisossomais. A vida média do autofagolisossomo é de cerca de dez minutos (MIZUSHIMA, 2007) e o resultado da autofagia no caso de desnutrição celular é a reciclagem de proteínas, lipídios e outras macromoléculas gerando nucleotídeos, aminoácidos e ácidos graxos para a síntese de ATP (DUSZENKO et al., 2011). Isso ocorre, por exemplo, com leveduras 
vivendo em ambientes deficientes em carbono e nitrogênio (MIZUSHIMA, 2007), em plantas vivendo em áreas sem fontes desses dois elementos químicos e em células de mamíferos depletadas de aminoácidos essenciais (DUSZENKO et al., 2011; LEVINE; MIZUSHIMA; VIRGIN, 2011). A autofagia celular também é induzida em situações fisiológicas como o remodelamento estrutural durante as fases de desenvolvimento do organismo (LEVINE; KROEMER, 2008) e em processos patológicos, como será discutido mais adiante. Vale salientar que já foram descritas três formas de autofagia: 1) autofagia mediada por chaperona, que necessita da interação de proteína do choque térmico (HSP70, heat shock protein) com macromoléculas alteradas do citoplasma, para desencadear o processo autofágico; 2) microautofagia, em que partes do citoplasma são englobadas diretamente pelos lisossomos e 3) macroautofagia ou autofagia, acima descrita e que consiste no tipo mais comum e melhor estudado (LI; BAO, 2012; LOOS et al., 2013).

Figura 1 - Aspectos do processo autofágico. A. Dupla membrana lipídica iniciando o englobamento de material citoplasmático. B. Fechamento da membrana, resultando no autofagossomo. C. Um lisossomo fundindo-se com o autofagossomo. D. Após a fusão e o material externo é degradado, e a estrutura denominada autofagolisossomo. E. Na foto em microscópio eletrônico vemos um macrófago, cultivado em meio de cultura pobre em nutrientes, fazendo autofagia. Note a dupla membrana do autofagossomo (Ma) próxima a uma mitocôndria (Mi), iniciando o seu englobamento. O núcleo da célula também é observado (N). O aumento é de 10.000 vezes.
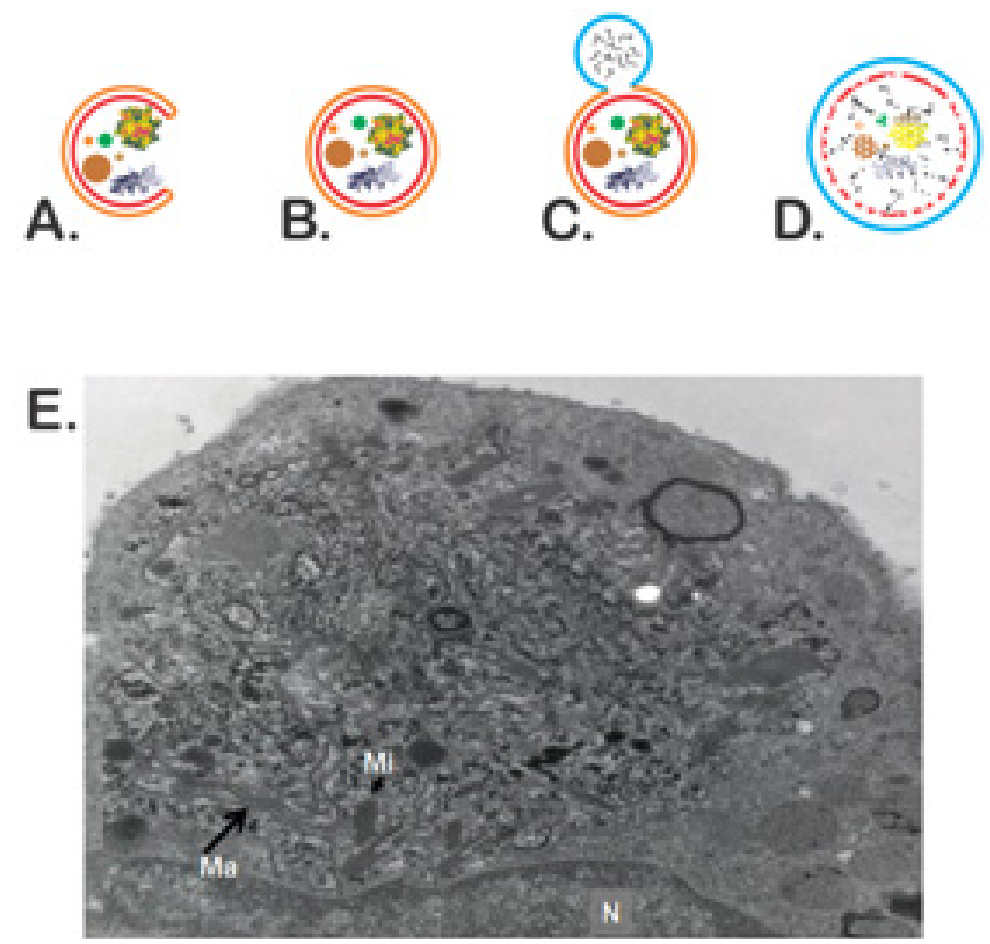

Fonte: Foto de Larissa Tavares Cyrino e Paulo Pinto Joazeiro, Unicamp. 
Aspectos moleculares da autofagia

As proteínas participantes foram identificadas a partir do estudo dos genes que controlam o processo autofágico. Os resultados iniciais foram obtidos do "screening" genético de leveduras mutantes, incapazes de fazer autofagia e de leveduras normais (TSUKADA; OHSUMI, 1993; YANG; KLIONSKY, 2010). De 1997 até os dias atuais, 30 genes que codificam proteínas, especialmente envolvidas na autofagia, foram identificados em leveduras, plantas e células de mamíferos (YANG; KLIONSKY, 2010). As proteínas ainda são pouco conhecidas do ponto de vista de suas interações moleculares, mas sabe-se do envolvimento de muitas delas nas diferentes fases da autofagia, como por exemplo: extensão e alongamento da membrana do autofagossomo; fechamento do autofagossomo em torno do material citoplasmático englobado; fusão com os lisossomos; digestão; reciclagem do material degradado (MIZUSHIMA, 2007). A lista dos 30 genes identificados, cujos produtos são diretamente relacionados a autofagia, são listados na Tabela 1. Por exemplo, Atg6 (abreviação de Autophagy-related) e Atg14 formam um complexo enzimático do tipo quinase que adiciona um grupo fosfato aos lipídios e funcionam como uma "pista de aterrissagem" para os lipídios que irão se alongar e formar a dupla bicamada lipídica da membrana do autofagossomo (YANG; KLIONSKY, 2010). Outras proteínas auxiliam na reciclagem do material degradado no autofagolisossomo, Atg22 medeia a eliminação dos aminoácidos e a lipase Atg15 digere os lipídios da membrana do autofagolisossomo após a digestão do material englobado (TETER et al., 2001). A Atg8, também conhecida como LC3, é uma proteína com função não definida, mas que está presente na membrana do autofagolisossomo; a conjugação com outras proteínas Atg (Atg3, Atg4, Atg16L) resulta na sua ligação com fosfatidilserina, surgindo então sua forma lipidada (LC3-lipidada) (KABEYA et al., 2000; MIZUSHIMA, 2007). Como LC3-lipidada está constantemente presente no processo autofágico, ela é usada como um marcador de autofagia.

Tabela 1 - Lista dos genes diretamente envolvidos na autofagia ${ }^{\mathrm{a}}$

\begin{tabular}{|c|c|c|}
\hline $\begin{array}{l}\text { Gene de Saccharomyces } \\
\text { cerevisae e eucariotos }\end{array}$ & $\begin{array}{l}\text { Gene de Homo } \\
\text { sapiens }\end{array}$ & Função da proteína \\
\hline ATG1 & ULK1 ULK2 & Quinase - reciclagem da membrana \\
\hline ATG2 & C14orf103 & $\begin{array}{l}\text { Proteína periférica da membrana - } \\
\text { formação do autofagossomo }\end{array}$ \\
\hline ATG3 & ATG3 & $\begin{array}{l}\text { Enzima conjugada a ubiquitina- indução e } \\
\text { regulação de autofagia }\end{array}$ \\
\hline ATG4 & $\begin{array}{l}A T G 4 A, A T G 4 B \\
A T G 4 C, A T G 4 D\end{array}$ & $\begin{array}{l}\text { Cisteína proteinase - clivagem da proteína } \\
\text { Atg8 }\end{array}$ \\
\hline ATG5 & ATG5 & $\begin{array}{l}\text { Proteína conjugada a proteína Atg12 - } \\
\text { formação do autofagossomo }\end{array}$ \\
\hline ATG6 & $B E C N 1$ & $\begin{array}{l}\text { Subunidade de quinase - extensão do } \\
\text { autofagossomo }\end{array}$ \\
\hline ATG7 & ATG7 & Enzima conjugada a ubiquitina \\
\hline$A T G 8, L C 3$ & $\begin{array}{l}\text { MAP1LC3A, } \\
A P 1 C 3 B \\
\text { GABARAPL, } \\
\text { GABARAPL1 }\end{array}$ & $\begin{array}{l}\text { Similar a ubiquitina - proteína conjugada } \\
\text { a diversas proteínas Atg }\end{array}$ \\
\hline ATG9 & $A T G 9 A, A T G 9 B$ & $\begin{array}{l}\text { Proteína transmembrana- alongamento do } \\
\text { autofagossomo }\end{array}$ \\
\hline
\end{tabular}




\begin{tabular}{|c|c|c|}
\hline ATG10 & ATG10 & Enzima conjugada a ubiquitina \\
\hline ATG11 & & $\begin{array}{l}\text { Proteína transportadora de Atg9 - indução } \\
\text { da autofagia }\end{array}$ \\
\hline ATG12 & ATG12 & $\begin{array}{l}\text { Similar a ubiquitina - extensão do } \\
\text { autofagossomo }\end{array}$ \\
\hline ATG13 & & $\begin{array}{l}\text { Proteína conjugada a proteína Atg1 - } \\
\text { indução da autofagia }\end{array}$ \\
\hline ATG14 & & $\begin{array}{l}\text { Subunidade de quinase - extensão do } \\
\text { autofagossomo }\end{array}$ \\
\hline$A T G 15$ & & $\begin{array}{l}\text { Lípase - digestão da membrana do } \\
\text { autofagolisossomo }\end{array}$ \\
\hline ATG16 & $A T G 16 L 1, A T G 16 L 2$ & $\begin{array}{l}\text { Proteína conjugada a proteína Atg5 - } \\
\text { formação do autofagossomo }\end{array}$ \\
\hline ATG17 & & $\begin{array}{l}\text { Subunidade de quinase - Regulação do } \\
\text { fechamento e tamanho de autofagossomo }\end{array}$ \\
\hline ATG18 & WIPI1, WIPI2 & Proteína conjugada a quinase - reciclagem \\
\hline ATG19 & & Proteína transportadora \\
\hline ATG20 & & $\begin{array}{l}\text { Proteína conjugada a quinase - } \\
\text { alongamento do autofagossomo }\end{array}$ \\
\hline ATG21 & & $\begin{array}{l}\text { Proteína conjugada a quinase - extensão e } \\
\text { alongamento do autofagossomo }\end{array}$ \\
\hline$A T G 22$ & $\begin{array}{l}A V T 3=S L C 36 A 1 \\
A V T 4=S L C 36 A 4\end{array}$ & $\begin{array}{l}\text { Proteína de membrana de vacúolos - } \\
\text { reciclagem de aminoácidos }\end{array}$ \\
\hline ATG23 & & Proteína periférica de membrana - fusão \\
\hline ATG24 & SNX30 & Proteína conjugada a quinase - fusão \\
\hline ATG25 & & $\begin{array}{l}\text { Proteína conjugada a diversas proteínas } \\
\text { Atg - fusão com vacúolos }\end{array}$ \\
\hline$A T G 26$ & & $\begin{array}{l}\text { Glicosiltransferase - alongamento do } \\
\text { autofagossomo }\end{array}$ \\
\hline ATG27 & & $\begin{array}{l}\text { Proteína transmembrana de mitocôndria e } \\
\text { Golgi - transportte de Atg9 }\end{array}$ \\
\hline ATG28 & & $\begin{array}{l}\text { Proteína conjugada a diversas proteínas } \\
\text { Atg - fusão com vacúolos }\end{array}$ \\
\hline ATG29 & & $\begin{array}{l}\text { Subunidade de quinase - indução de } \\
\text { autofagia }\end{array}$ \\
\hline ATG30 & & Proteína conjugada a Atg11 \\
\hline
\end{tabular}

${ }^{a}$ Lista dos genes denominados ATG (autophagy-related gene) e identificados em C. cerevisae e vários organismos eucariotos.

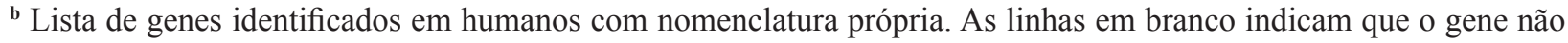
foi identificado em humanos.

Fonte: Rubinsztein et al., 2007 e Yang; Klionsky, 2010.

\section{Técnicas de medição de autofagia}

Para a descrição detalhada de um dado fenômeno biológico é necessário identificá-lo e medi-lo apropriadamente e, idealmente, por mais de um método experimental. No caso da autofagia, inicialmente, a analise ultra-estrutural era a única ferramenta de estudo (YANG; KLIONSKY, 2010). Essa técnica permite a visualização com aumentos de 5 mil a 500 mil vezes e fornece informações analíticas que não são reveladas com nenhuma outra técnica. De fato, o autofagossomo com seu sistema de dupla bicamada lipídica, incomum 
em outras organelas, é relativamente fácil de identificar pela microscopia eletrônica (YANG; KLIONSKY, 2010). No entanto, as desvantagens do microscópio eletrônico são o alto custo e o fato dele gerar apenas dados qualitativos. A partir da década de 1990, diferentes técnicas moleculares foram desenvolvidas para o estudo da dinâmica do processo autofágico (CUERVO; SEGLEN, 2007) e atualmente há métodos robustos e disponíveis comercialmente, como o uso dos corantes fluorescentes que se acumulam em compartimentos celulares com $\mathrm{pH}$ ácido. Um desses compostos é o LysoTracker red $\AA$, um fluoróforo ligado a uma amina, base fraca que é protonada $\left(\right.$ ganha $\mathrm{H}^{+}$) e emite níveis altos de fluorescência em meio ácido, como aquele encontrado nos autofagolisossomos (MITOU; BUDAK; GOZUACIK, 2009). Outro método usado, baseia-se em uma das características de células autofágicas, a degradação de proteínas. As células cultivadas em meio de cultura com aminoácidos radioativos (leucina $\mathrm{H}^{3}$ ou valina $\mathrm{C}^{14}$ ) e depois deixadas em meio sem aminoácidos perdem rapidamente a radiatividade porque têm altas taxas de degradação protéica, comparadas as células normais (MIZUSHIMA, 2004). Apesar da facilidade técnica para a realização dessas duas metodologias, a disponibilidade e o baixo custo, a desvantagem é a baixa especificidade de ambas. De fato, células tem outros compartimentos com $\mathrm{pH}$ ácido que podem acumular os corantes fluorescentes e há situações de estresse em que podem ocorrer degradação proteica sem autofagia. Assim, o uso de marcadores moleculares específicos para autofagia é determinante para as pesquisas. Até o presente, poucas moléculas foram detectadas exclusivamente durante a autofagia (MIZUSHIMA, 2007, MITOU et al., 2009) mas a proteína LC3 na sua forma lipidada, é uma delas. Anticorpos produzidos em camundongos e coelhos contra LC3 são comercializados e utilizados em diferentes ensaios (imunofluorescência, imunoblot, entre outros) para detecção e quantificação da autofagia (KLIONSKY; CUERVO; SEGLEN, 2007), entretanto, alguns tipos celulares expressam constantemente LC3 mesmo quando cultivadas sem estresse (MIZUSHIMA, 2007). O estudo de novos marcadores ainda mais específicos que possibilitem o monitoramento da dinâmica do processo autofágico é importante e está em curso em diversos laboratórios. O que se preconiza é o uso de três ou mais métodos aqui descritos para análise da autofagia em células e modelos animais experimentais.

\section{A autofagia e os processos patológicos}

Na última década, pesquisadores começaram a se perguntar se ocorria autofagia durante processos patológicos, incluindo doenças infecciosas (OVERDAHL; LEVINE, 2008; LEVINE; MIZUSHIMA; VIRGIN, 2011). As células infectadas com microrganismos estão sob estresse, pois tem suas reservas energéticas depletadas e precisam livrar-se do invasor. A maquinaria autofágica poderia propiciar a reciclagem de macromoléculas e/ou englobamento e degradação do microrganismo nos autofagolisossomos (SHINTANI; KLIONSKY, 2004). De fato, bactérias tais como Streptococcus pyogenes causadora de rinofaringites, infecção de feridas cirúrgicas e síndrome do choque tóxico (NAKAGAWA et al., 2004), Salmonella enterica responsável por gastrenterites e febre tifóide (Hernandez et al., 2003), Listeria monocytogenes causadora de meningoencefalite, encefalite e infecção cervical ou intra-uterina em gestantes (RICH; BURKETT; WEBSTER, 2003) e os vírus da hepatite $\mathrm{C}$ e herpes simplex, induzem autofagia nas células infectadas (ALEXANDER et al., 2007; DREUX et al., 2009). A planta leguminosa Astragalus sinicus (astrágalo chinês) quando desnutrida é capaz de eliminar uma bactéria simbionte não patogênica, a Mesorhizobium hauakuii por via autofágica (KOBAYASHI et al., 2001). Recentemente, em nosso laboratório, estávamos interessados em saber se a infecção com o parasita Leishmania induziria autofagia no hospedeiro, e qual seria a sua importância para esse microrganismo e sua célula hospedeira, os 
macrófagos humanos e de outros animais (CYRINO et al., 2012). Os macrófagos são células do sistema imune com diversas funções, entre elas a fagocitose de material estranho, e circulam por todos os órgãos do nosso organismo (GIORGIO, 2013). Leishmania é um parasita unicelular transmitido pela picada de um inseto hematófago (flebótomo) e que vive dentro de vacúolos parasitóforos do macrófago. A Leishmania que estudamos é da espécie amazonensis e provoca lesão cutânea ou uma forma grave, a leishmaniose cutânea difusa, resistente ao tratamento convencional (GRIMALDI; TESH, 1993). Ainda não há vacinas comerciais para as leishmanioses humanas, o tratamento pode ocasionar efeitos colaterais e nem sempre é eficaz (NYLEN; GAUTAM, 2010). Os principais modelos de estudo dessa parasitose, envolvem o cultivo do parasita e dos macrófagos isolados de animais e sangue humano, e a infecção de camundongos isogênicos da linhagem Balb/c (ARAÚJO et al., 2012; COLHONE et al., 2004; ARRAIS-SILVA et al., 2006). Um grupo de pesquisadores da Fiocruz e UFRJ (PINHEIRO et al., 2009) mostraram que, dependendo da origem dos macrófagos, a indução de desnutrição altera o grau de infecção com L. amazonensis. Pesquisadores da Grécia (MITROULIS et al., 2009), usando teste com o marcador LC3 mostraram que macrófagos de um paciente com leishmaniose estavam autofágicos. Nosso grupo foi um pouco além e utilizando três métodos diferentes (microscopia eletrônica, marcador LC3 e o LysoTracker red $\AA$ ) detectou autofagia em culturas de macrófagos infectados com L. amazonensis (CYRINO et al., 2012). Os autofagossomos estavam por todo o citoplasma e alguns próximos do grande vacúolo que abriga o parasita. Nosso grupo também observou que lesões cutâneas de vários camundongos infectados com L. amazonensis tinham macrófagos autofágicos. E quando os macrófagos cultivados e infectados foram impedidos de fazer autofagia, após o tratamento com o inibidor de autofagia 3-metiladenina, a carga parasitária, isto é, o numero de parasitas intracelulares, decaiu (CYRINO et al., 2012). As conclusões desses experimentos são as seguintes: macrófagos fazem autofagia quando estão infectados com L. amazonensis e o processo autofágico é importante durante a infecção, não só para o próprio macrófago que precisa sobreviver ao parasitismo, mas também para a Leishmania, que deve aproveitar do material reciclado durante a autofagia, como fonte de alimento. Esses dados abrem caminho para responder outras questões, como por exemplo, como o material reciclado é aproveitado pelo parasita e se outras espécies de Leishmania também induzem autofagia, e ainda para o desenvolvimento de compostos que alterem o processo autofágico nas células hospedeiras infectadas, possibilitando o controle dessa parasitose.

Como mencionado acima, além de mobilizar e reciclar nutrientes durante fases de desnutrição e outras situações de estresse, a autofagia ocorre normalmente em níveis basais com a função de eliminar macromoléculas/organelas defeituosas ou avariadas (LEVINE, 2007; MIZUSHIMA, 2007; LEVINE; MIZUSHIMA; VIRGIN, 2011). O processoautofágicoestárelacionadoaoaparecimento de algumas doenças neurodegenerativas (SHINTANI; KLIONSKY, 2004; LEVINE; YUAN, 2005). O acumulo de agregados protéicos tóxicos é uma das características de doenças como Alzheimer, Huntington e Parkinson (OSELLANE; DUCHEN, 2013). Os pesquisadores têm evidencias que defeitos na maquinaria autofágica de células neuronais de pacientes com essas doenças resultam no acumulo de proteínas neurotóxicas, isto é, há neurônios que não se "limpam" adequadamente, por meio da autofagia (SHINTANI; KLIONSKY, 2004). Ainda não se conhece o tipo ou tipos de defeitos que impossibilitam a autofagia, mas já se sabe que um fármaco indutor da autofagia, a rapamicina, atenua os sintomas de camundongos com doença de Huntington (FLOTO et al., 2007; MARTINEZVICENTE et al., 2010). Resultados promissores são esperados para os próximos anos. 
No câncer a autofagia parece desempenhar papeis importantes, e apesar dos intensos estudos, sua atuação ainda é objeto de debate (LEVINE, 2007; LOS et al., 2013). Por exemplo, há dados mostrando que camundongos com defeito genético na produção de uma das proteínas que integram a maquinaria autofágica (beclin 1) desenvolvem muitos tumores, e a expressão aumentada de alguns genes ligados a autofagia (beclin 1 e atg5) inibe a formação de tumores de mama em camundongos (LEVINE, 2007; YANG; KLIONSKY, 2011). Paralelamente, observou-se que genes supressores de tumores (p53 e PTEN), que frequentemente sofrem mutações em células tumorais humanas, podem ativar a via autofágica, enquanto genes ativos em células cancerosas como PI3K e AKT inibem a autofagia (LEVINE, 2007; JANKU et al., 2011). A hipótese para explicar esses dados, propõe que a autofagia age como um supressor de tumor, porque células incapazes de fazer autofagia acumulam macromoléculas defeituosas, isto é, seu controle de qualidade é falho, e desenvolvem fenótipos tumorais. Mas há trabalhos que vão em direção oposta. Como por exemplo, a analise da expressão da proteína LC3 em 163 biópsias de tumores gastrointestinais, que apontou a superexpressão dessa proteína marcadora de autofagia em 53\% dos casos de cânceres de esôfago, 58\% dos tumores gástricos e 63\% dos cânceres coloretais (YOSHIKA et al., 2008; JANKU et al., 2011); apesar de sua presença não se correlacionar com bom ou mal prognóstico. Os resultados de testes pré-clínicos indicam que drogas anticâncer induzem autofagia nas células tumorais, mas que inibidores genéticos e farmacológicos da autofagia sensibilizam células tumorais para os efeitos da quimio- e radioterapia em modelos pré-clinicos (Moreselli, et al., 2009; Morselli et al., 2011; JANKU et al., 2011; LOOS et al., 2013). A visão mais aceita atualmente é de que a autofagia age como mecanismo supressor de tumores em fases inicias da oncogênese, mas que também pode proteger a célula tumoral, quando esta se encontra em situação de estresse, como durante os tratamentos. Há testes clínicos sendo realizados nos EUA com análogos da rapamicina, um indutor da autofagia, em pacientes com glioma (um tipo de tumor cerebral) (KIRKEGAARD et al., 2004; SARKARIA et al., 2010). Atualmente, há grupos de pesquisa em todo o mundo, inclusive no Brasil, que avaliam em laboratório, os efeitos antitumorais de outros fármacos indutores e inibidores da autofagia (ZAMIN et al., 2009; CALGAROTTO et al., 2012; BORDIN et al., 2013).

\section{Conclusão}

A autofagia, um fenômeno biológico, descrito e estudado inicialmente por citologistas, presente durante toda a história evolutiva e relacionado a proteção celular em situações de estresse, mostrase bastante complexo com os atuais estudos moleculares. Há várias questões ainda a serem elucidadas neste processo. Apesar de se conhecer a dinâmica ultraestrutural da célula autofágica em que uma membrana dupla bilipídica engloba porções do seu citoplasma ou até de organelas inteiras originando o autofagossomo e que este irá fusionar-se com os lisossomos gerando o autofagolisossomo, a procedência dessa membrana é controversa e necessita de maiores investigações. As proteínas envolvidas na autofagia também são pouco conhecidas do ponto de vista de suas interações moleculares. A pesquisa de novos marcadores de autofagia mais específicos e que possibilitem o melhor monitoramento da dinâmica do processo autofágico é importante e está em curso em diversos laboratórios. Apesar da autofagia ter sido demonstrada em doenças neurodegenerativas e processos infecciosos como na leishmaniose e de experimentos in vitro mostrarem que sua modulação modifica o destino dos microrganismos nas células hospedeiras, o preciso papel durante essas doenças, os tipos de defeitos que impossibilitam seu funcionamento e o potencial terapêutico de inibidores/indutores precisam ser ainda extensivamente avaliados. Em 
relação ao câncer muitas perguntas relacionadas aos papeis antagônicos da autofagia como supressora de tumores nas fases inicias da oncogênese ou protetora da célula tumoral, quando esta se encontra em situação de estresse, como nos tratamentos, devem ser respondidas. Desta forma, espera-se que em um futuro próximo, várias questões sobre esse importante fenômeno biológico sejam elucidadas.

\section{Agradecimentos}

Fundação de Amparo a Pesquisa do Estado de São Paulo e Conselho Nacional de Desenvolvimento Cientifico e Tecnológico.

\section{Referências}

ALEXANDER, D. E.; WARD S. L.; MIZUSHIMA, N.; LEVINE, B.; LEIB, D. A.; Analysis of the role of autophagy in replication of herpes simplex virus in cell culture. Cell Molecular Life Science, New York, v. 69, n. 7, p. 1125-1136, 2012.

ARAÚJO, A. P.; ARRAIS-SILVA, W. W.; GIORGIO, S. Infection by Leishmania amazonensis in mice: a potential model for chronic hypoxia. Acta Histochemica, Amsterdam, v. 114, n. 8, p. 797-804, 2012.

ARRAIS-SILVA, W.W.; PINTO, E.F.; ROSSIBERGMANN, B.; GIORGIO, S. Hyperbaric oxygen therapy reduces the sizes of Leishmania amazonensis-induced soft tissues lesions in mice. Parasitology International, Amsterdam, v. 98, n. 2, p. 130-136, 2006.

ASHFORD, T. P; PORTER, K. R. Cytoplasmic components in hepatic cell lysosomes. The Journal of Cell Biology, New York, v. 12, p. 198-202, 1962.

BORDIN, D. L.; LIMA, M.; LENZ, G.; SAFFI, J.; MEIRA, L. B.; MÉSANGE, P.; SOARES, D. G.; LARSEN, A. K.; ESCARGUEIL, A. E.; HENRIQUES, J. A. DNA alkylation damage and autophagy induction. Mutation Research, Amsterdam, pii: S1383-5742(13)00048-3. doi: 10.1016/j.mrrev.2013.07.001, 2013.
CALGAROTTO, A. K.; DA SILVA PEREIRA, G. J.; BECHARA, A.; PAREDES-GAMERO, E. J.; BARBOSA, C. M.; HIRATA, H.; DE SOUZA QUEIROZ, M. L.; SMAILI, S. S.; BINCOLETTO, C. Autophagy inhibited Ehrlich ascitic tumor cells apoptosis induced by the nitrotyrene derivative compounds: relationship with cytosolic calcium mobilization. European Journal of Pharmacology, Berlin, v. 678, n. 1-3, p. 6-14, 2012.

COLHONE, M. C.; ARRAIS-SILVA, W. W.; PICOLI, C.; GIORGIO, S. Effect of hypoxia on macrophage infection by Leishmania amazonensis. Journal of Parasitology, Lawrence, v. 90, n. 3, p, 510-515, 2004.

CYRINO, L.T.; ARAÚJO, A. P.; JOAZEIRO P. P.; VICENTE, C. P.; GIORGIO, S. In vivo and in vitro Leishmania amazonensis infection induces autophagy in macrophages. Tissue and Cell, Edinburgh, v. 44, n. 6, p. 401-408, 2012.

DE DUVE, C.; WATTIAUX, R. Functions of lysosomes. Annual Review of Physiology, Palo Alto, v. 28, p. 435-492, 1966.

DREUX, M.; GASTAMINZA, P.; WIELAND, S. F.; CHISARI, F. V. The autophagy machinery is required to initiate hepatitis $\mathrm{C}$ virus replication. Proceedings of the National Academy of Science US A, Washington, v. 106, n. 33, p. 14046-14051, 2009.

DUSZENKO, M.; GINGER, M. L.; BRENNAND, A., GUALDRÓN-LÓPEZ, M.; COLOMBO, M. I.; COOMBS, G. H.; COPPENS, I.; JAYABALASINGHAM. B.; LANGSLEY, G.; DE CASTRO, S L.; MENNA-BARRETO, R.; MOTTRAM, J. C.; NAVARRO M.; RIGDEN, D. J.; ROMANO, P. S.; STOKA, V.; TURK, B.; MICHELS, P. A. Autophagy in protists. Autophagy, Georgetown, vol. 7, n. 2, p. 127-158, 2011.

FLOTO, R. A.; SARKAR, S.; PERLSTEIN, E. O.; KAMPMANN, B.; SCHREIBER, S. L.; RUBINSZTEIN, D. C. Small molecule enhancers of rapamycin-induced TOR inhibition promote autophagy, reduce toxicity in Huntington's disease models and enhance killing of mycobacteria by macrophages. Autophagy, Georgetown, v. 3, n. 6, p. 620-622, 2007. 
GIORGIO, S. Macrophages: plastic solutions to environmental heterogeneity. Inflammation Research, Basel, v. 62, n. 9, p. 835-843.

GRIMALDI, G. JR; TESH, R. B. Leishmaniases of the New World: current concepts and implications for future research. Clinical Microbiology Reviews, Washington, v. 6, n. 3, p. 230-250, 1993.

JANKU, F.; MCCONKEY, D. J.; HONG, D. S.; KURZROCK, R. Autophagy as a target for anticancer therapy. Nature Reviews. Clinical Oncology, London, v. 8, n. 9, p. 528-539, 2011.

KABEYA, Y.; MIZUSHIMA, N.; UENO, T.; YAMAMOTO, A.; KIRISAKO, T.; NODA, T.; KOMINAMI, E.; OHSUMI, Y.; YOSHIMORI, T. LC3, a mammalian homologue of yeast Apg8p, is localized in autophagosome membranes after processing. The EMBO Journal, Oxford, v. 19, n. 21, 5720-5728, 2001.

KIRKEGAARD, K.; TAYLOR, M. P.; JACKSON, W. T. Cellular autophagy: surrender, avoidance and subversion by microorganisms. Nature Review Microbiology, London, v. 2, n. 4, p. 301-314, 2004.

KLIONSKY, D. J.; CUERVO, A. M.; SEGLEN, P. O. Methods for Monitoring Autophagy from Yeast to Human. Autophagy, Edinburgh, v. 3, n. 3, p. 181206, 2007.

KLIONSKY, D. J. Autophagy revisited: a conversation with Christian de Duve. Autophagy, Edinburgh, v. 4, n. 6, p. 740-743, 2008.

KOBAYASHI, H.; SUNAKO, M.; HAYASHI, M.; MUROOKA, Y.; DNA synthesis and fragmentation in bacteroids during Astragalus sinicus root nodule development. Bioscience Biotechnology and Biochemistry, Tokyo, v. 65, n. 3, p. 510-515, 2001.

LEVINE, B.; DERETIC, V. Unveiling the roles of autophagy in innate and adaptive immunity. Nature Reviews Immunology, London, v. 7, p. 67-77, 2007.

LEVINE, B.; KLIONSKY, D. J. Development by selfdigestion: molecular mechanisms and biological functions of autophagy. Developmental Cell, Cambridge, v. 6, p. 463-477, 2004.
LEVINE, B.; KROEMER, G. Autophagy in the pathogenesis of Disease. Cell, Cambridge, v. 132, n. 1, p. 27-42, 2008.

LEVINE, B.; YUAN, J. Autophagy in cell death: an innocent convict? The Journal of Clinical Investigation, Ann Arbor, v. 115, n. 10, p. 26792688, 2005.

LEVINE, B. Cell biology: autophagy and cancer. Nature, London, v. 446, n. 7137, p. 745-747, 2007.

LEVINE, B.; MIZUSHIMA, N.; VIRGIN, H. W. Autophagy in immunity and inflammation. Nature, London, v. 469, n. 7330, p. 323-329, 2011.

LI, W. W.; LI, J.; BAO, J. K.; Microautophagy: lesser-known self-eating.Cell Mol Life Sci, v. 69, n. 7, p. 1125-36, 2012

LOOS, B.; ENGELBRECHT, A. M.; LOCKSHIN, R. A.; KLIONSKY, D. J.; ZAKERI, Z. The variability of autophagy and cell death susceptibility: Unanswered questions. Autophagy, Georgetown, v. 9, n. 9, Epub ahead of print, 2013.

MARTINEZ-VICENTE， M.; TALLOCZY， Z.; WONG, E.; TANG, G.; KOGA, H.; KAUSHIK, S.; DE VRIES, R.; ARIAS, E.; HARRIS, S.; SULZER, D.; CUERVO, A. M. Cargo recognition failure is responsible for inefficient autophagy in Huntington's disease. Nature Neuroscience, London, v. 13, n. 5, p. 567-576, 2010.

MITOU, G.; BUDAK, H.; GOZUACIK, D. Techniques to study autophagy in plants. International Journal of Plant Genomics, New York, 451357, doi: 10.1155/2009/451357, 2009.

MITROULIS, I.; KOURTZELIS, I.; PAPADOPOULOS, V.P.; MIMIDIS, K.; SPELETAS, M.; RITIS, K. In vivo induction of the autophagic machinery in human bone marrow cells during Leishmania donovani complex infection. Parasitology International, Amsterdam, v. 58, p. 475-477, 2009.

MIZUSHIMA, N. Autophagy: Process and functions. Genes \& Development, Cold Spring Harbor, v. 21, p. 2861-2873, 2007. 
MIZUSHIMA, N. Methods for monitoring autophagy. International Journal of Biochemistry \& Cell Biology, Exeter, v. 36, p. 2491-502, 2004.

MORSELLI, E.; GALLUZZI, L.; KEPP, O.; MARIÑO, G.; MICHAUD, M.; VITALE, I.; MAIURI, M. C.; KROEMER, G. Oncosuppressive functions of autophagy. Antioxidant Redox Signal, Larchmont, v. 14, n. 11, p. 2251-2269, 2011

MORSELLI, E.; GALLUZZI, L.; KEPP, O.; VICENCIO, J. M.; CRIOLLO, A.; MAIURI, M. C.; KROEMER, G. Anti- and pro-tumor functions of autophagy. Biochimica Biophys Acta, Amsterdam v. 1793, n. 9, p. 1524-1532, 2009.

NAKAGAWA, I.; AMANO, A.; MIZUSHIMA, N.; YAMAMOTO, A.; YAMAGUCHI, H.; KAMIMOTO T.; NARA, A.; FUNAO, J.; NAKATA, M.; TSUDA, K.; HAMADA, S.; YOSHIMORI, T. Autophagy defends cells against invading group $A$ Streptococcus. Science, Washington, v. 306, n. 5698, p. 1037-1040, 2004.

NOVIKOFF, A. B. The proximal tubule cell in experimental hydronephrosis. The Journal of Biophysics Biochemistry and Cytology, New York, v. 6, p. 136-138, 1959.

NYLÉN, S. \& GAUTAM, S. Immunological perspectives of leishmaniasis. Journal of Global Infectious Diseases, Mumbai, v. 2, n. 2, p. 135-146, 2010.

ORVEDAHL, A. \& LEVINE, B. Eating the enemy within: autophagy in infectious diseases, Cell Death and Differentiation, London, v. 16, n. 1, p. 57, 2009.

OSELlAME, L. D. \& DUCHEN, M. R. Defective quality control mechanisms and accumulation of damaged mitochondria link Gaucher and Parkinson diseases. Autophagy, Georgetown, v. 9, n. 10, Epub ahead of print, 2013.

PINHEIRO, R.O.; NUNES, P.N.; PINHEIRO, C.S.; D`AVILAH.;BOZZA,P.T.; TAKIYA, C.M.; CORTEREAL, S.; FREIRE-DE-LIMA. C. G.; DOS REIS G. A.; 2009. Induction of autophagy correlates with increased parasite load of Leishmania amazonensis in BALB/c but not C57BL/6 macrophages. Microbes and Infection, Paris, v. 11, p. 181-90, 2009.
RICH, K. A.; BURKETT, C.; WEBSTER, P. Cytoplasmic bacteria can be targets for autophagy. Cellular Microbiology, Oxford, v. 5, n. 7, p. 455468, 2003.

RUBINSZTEIN D. C, GESTWICKI JE, MURPHY LO, KLIONSKY DJ. Potential therapeutic applications of autophagy. Nature Review Drug Discovery, London, v. 6, n. 4, p. 304-312, 2007.

SARKARIA, J. N.; GALANIS, E.; WU, W.; DIETZ, A. B.; KAUFMANN, T. J.; GUSTAFSON, M. P.; BROWN, P. D.; UHM, J. H.; RAO, R. D.; DOYLE, L.; GIANNINI, C.; JAECKLE, K. A.; BUCKNER, J. C. Combination of temsirolimus (CCI-779) with chemoradiation in newly diagnosed glioblastoma multiforme (GBM) (NCCTG trial N027D) is associated with increased infectious risks. Clinical Cancer Research, Denville, v. 16, n. 22, p. 55735580, 2010.

SCHIMID, D; MUNZ, C. Innate and adaptive immunity through autophagy. Immunity, Cambridge, v. 27, p. 11-21, 2007.

SHINTAMI, T.; KLIONSKY, D.J. Autophagy in heatlth and disease: a double-edged sword. Science, Washington, v. 306, p. 990-995, 2004.

TETER, S. A.; EGGERTON, K. P.; SCOTT, S. V.; KIM, J.; FISCHER, A. M.; KLIONSKYK, D. J. Degradation of lipid vesicles in the yeast vacuole requires function of Cvt17, a putative lipase. The Journal of Biological Chemistry, Rockville Pike, v. 276, n. 3, p. 2083-2087, 2001.

TSUKADA, M.; OHSUMI, Y. Isolation and characterization of autophagy-defective mutants of Saccharomyces cerevisiae. FEBS Letters, Amsterdam, v. 333, n. 1-2, p. 169-174, 1993.

YANG, Z.; KLIONSKY, D. J. Eaten alive: a history of macroautophagy, Nature Cell Biology, London, v. 12, n. 9, p. 814-822, 2010.

YOSHIOKA, A.; MIYATA, H.; DOKI, Y.; YAMASAKI, M.; SOHMA, I.; GOTOH, K.; TAKIGUCHI, S.; FUJIWARA, Y; UCHIYAMA, Y.; MONDEN, M. LC3, an autophagosome marker, is highly expressed in gastrointestinal cancers. International Journal of Oncology, Athens, v. 33, n. 3, p. 461-468, 2008. 
ZAMIN, L.L.; FILIPPI-CHIELA, E. C.; DILLENBURG-PILLA, P.; HORN, F.; SALBEGO, C.; LENZ, G. Resveratrol and quercetin cooperate to induce senescence-like growth arrest in C6 rat glioma cells. Cancer Science, Oxford, v. 100, n. 9, p.1655-1662, 2009.

Recebido em: 10 jul. 2013.

Aceito em: 27 jan. 2014. 